EDITORIAL

\title{
OBSTETRICS AND GYNECOLOGY PRACTICE AND PROFESSIONAL COUNSELING FOR MEDICAL STUDENTS GRANT
}

This year, from July to November, the Obstetrics and Gynecology Department from "Bucur" Maternity "Saint John" Hospital, Bucharest conducted the POSDRU grant "Obstetrics and Gynecology Practice and Professional Counseling for Medical Students". The project had the financial support of both the European Social Fund and the Sectorial Operational Program for Human Resources Development 2007-2013, priority axis 2.

The main objective of the Grant was to support students from University of Medicine and Pharmacy "Carol Davila" Bucharest in the transition and integration from study to real professional life. More than 160 students of the 2nd to 5th year of university were included in the project. Each student had the opportunity attend the practice for a period of 3 weeks, 6 hours per day, similar to a normal working day of a doctor.

The core of the activity was real, medical practice. The students had the occasion to practice gynecological and surgical everyday gestures such as knots and sutures, to attend in the operating room during gynecological interventions or caesarian sections, but also to be involved in attending vaginal deliveries or performing obstetrics ultrasound by themselves. During that period the students spent 2 weeks of activity in "Bucur" Maternity and one week in the Medical Simulating Center "LifeSiM". In this specialized center they had the opportunity to practice laparoscopy, hysteroscopy, knots and sutures, basic life support maneuvers and vaginal birth assistance on medical models.

The originality of the program was that the physicians who trained the students had no universitary activity in their current life. They were enthusiast young specialists or residents in obstetrics. In this way the students felt closeer to their instructors and integrated easyly in the hospital life. Being trainers, the physicians experienced that challenge and had good result in teaching the students that was an aspect observed from final students feed-back.

Why was the project so important? Our practice program is unique because it is the first one who developed such activity in obstetric filed in a simulating center. Moreover, we offered also professional carrier counseling to the students and the most emotional involvement that we could. We considered each student as a less experienced colleague and we tried to explain everything the best we could. The bound created during the program with some of them lead to volunteering for some of them who continued to come in our hospital.

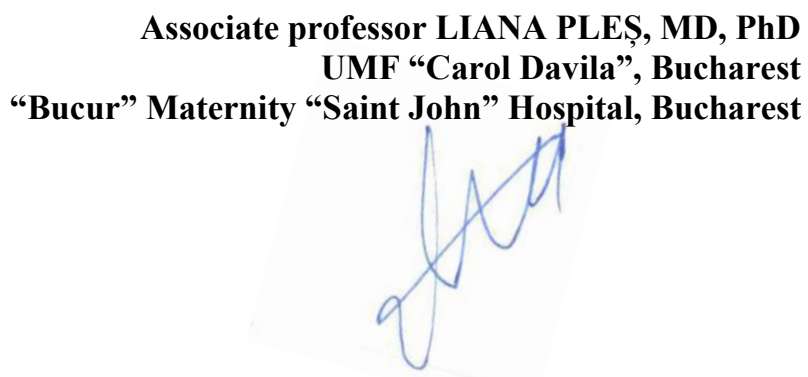

